\title{
POTENTIAL APPLICATION OF PULSED ELECTRIC FIELDS TO IMPROVE THE RECOVERY OF BIOACTIVE COMPOUNDS FROM SOUR CHERRIES AND THEIR BY-PRODUCTS
}

\author{
Ramune Bobinaite ${ }^{1 *}$, Gianpiero Pataro ${ }^{2}$, Mindaugas Visockis ${ }^{1}$, Česlovas Bobinas ${ }^{1}$, Giovanna Ferrari ${ }^{2,3}$, Pranas Viškelis ${ }^{1}$ \\ I*Institute of Horticulture, Lithuanian Research Centre for Agriculture and Forestry, Kaunas st. 30, Babtai LT-54333, Kaunas dist., \\ Lithuania,e-mail: r.bobinaite@ldsi.lt \\ ${ }^{2}$ Department of Industrial Engineering, University of Salerno, Via Giovanni Paolo II, 132, 84084 Fisciano (SA), Italy \\ ${ }^{3}$ ProdAl Scarl, Via Ponte don Melillo, 84084 Fisciano (SA), Italy
}

\begin{abstract}
Pulsed electric fields (PEF) treatment induces transmembrane potential by means of an externally applied electric field of sufficient intensity, which causes an increase in the permeability of a cell membrane. PEF can be applied for plant cell disruption as upstream step to enhance the efficiency of mass transfer in further processing such as hydraulic pressing or extraction. The objective of the study was to evaluate the potential of using PEF technology for the increase of the juice yield and improved extraction of bioactive compounds from sour cherries (Prunus cerasus L.) and their by-products. PEF treatments $\left(1-5 \mathrm{kV} \mathrm{cm}^{-1}\right.$ at $\left.10 \mathrm{~kJ} \mathrm{~kg}^{-1}\right)$ were applied to cherries before the juice pressing. The by-products (press cake) generated were extracted with aqueous methanol. The samples from PEF pre-treated cherries and their by-products were compared to both untreated (control) samples and samples obtained from freezethawed (PEF untreated) cherries. The highest increase in juice yield by $45 \%$ was obtained at PEF intensity of E $=3 \mathrm{kV} \mathrm{cm}{ }^{-1}$, showing similar results to freeze-thawed sample $(41 \%)$. The application of PEF significantly increased the release of total anthocyanins (48.3-53.3 mg $\left.100 \mathrm{~mL}^{-1}\right)$ and total phenolics (126.6-133.9 mg $\left.100 \mathrm{~mL}^{-1}\right)$ into juice as compared with the control (33.8 and $112.9 \mathrm{mg}$ $100 \mathrm{~mL}^{-1}$, respectively), whereas juice from freeze-thawed sample exhibited the highest value only for total phenolics content (164.4 mg $100 \mathrm{~mL}^{-1}$ ). The extracts from by-products obtained after PEF assisted juice pressing of cherries showed significantly higher contents of bioactive compounds and higher antioxidant power as compared with the control extract and the extract of freezethawed sample. Overall, the results of this work demonstrated promising use of PEF technology in sour cherry processing.
\end{abstract}

Keywords: PEF, extraction, juice pressing, by-products, phenolics.

\section{Introduction}

Sour cherries (Prunus cerasus L) (also called tart cherries) are an important source of anthocyanins and other phytochemicals that possess many potential biological properties (Damar et al., 2012; Šarić et al., 2009). Studies have demonstrated that sour cherries exhibit anticarcinogenic effect in various colon cancer models (Ferreti et al., 2010). Furthermore, anthocyanins were identified as anti-inflammatory agents, which are major contributors to the antioxidant activity in cherries (Ferreti et al., 2010; Repajić et al., 2015).

The total anthocyanin content of sour cherries is reported to range from 28 to $80 \mathrm{mg} 100 \mathrm{~g}^{-1}$ (Blando et al., 2004). However, the total anthocyanin content and composition differ depending on sour cherry genotype (Blando et al., 2004; Damar, Eksi, 2012).

Processing of fruits and vegetables affects their phytochemical and nutrient content, which may also influence their related health benefits (Ou et al., 2012). Therefore, there is a need to study the potential of new, non-thermal processing technologies, such as pulsed electric fields (PEF) that can enhance the recovery of high-added value components from plant materials without having negative effect on nutritional or sensorial attributes of the final product. PEF processing involves the application of a high intensity electric fields in the form of short pulses to a food placed between two electrodes. PEF induces permeabilization of cell membranes (electroporation), which facilitates the release of intracellular substances. It has been demonstrated that PEF pre-treatment can enhance hydraulic pressing efficiency, diffusion rate and increase the yield in production of several fruit and vegetable juices (Mahnic-Kalamiza et al., 2014). However, to date, no work dealt with the use of PEF to assist expression of juice from sour cherries and the subsequent valorization of cherries by-product (press cake). Therefore, the objective of the study was to evaluate the potential of using PEF technology for the increase of the juice yield and bioactive compounds extraction from sour cherries (Prunus cerasus L.) and their by-products.

\section{Materials and Methods}

A pulsed electric fields treatment was applied using an electric field generator (Modulator PG, ScandiNova, Uppsala, Sweden) able to deliver monopolar square pulses. The PEF treatment of sour cherries was carried out in a cylindrical batch treatment chamber with uniformly pierced $(\mathrm{d}=0.5 \mathrm{~mm})$ lateral surface, closed at both ends by two stainless steel electrodes $(3.4 \mathrm{~cm}$ in diameter).

During each experiment, $10 \mathrm{~g}$ of sour cherries (destoned and cut into 4 pieces) were loaded into the treatment chamber and subjected to PEF treatments at different electric field strength $\left(\mathrm{E}=1,3\right.$, and $\left.5 \mathrm{kV} \mathrm{cm}^{-1}\right)$, constant total specific energy input $\left(W_{T}=10 \mathrm{~kJ} \mathrm{~kg}^{-1}\right)$, constant frequency $(10 \mathrm{~Hz})$ and pulse width of $20 \mu \mathrm{s}$. PEF-treated samples were then pressed in the treatment chamber by loading a weight on the top of upper electrode (10 kg weight for 9 minutes). The expressed liquid was centrifuged to obtained clear juice, which was subjected to further analysis. The subsequent extraction of press cakes left after juice pressing was performed with acidified aqueous methanol 
$(70 \% \mathrm{MeOH}$ and $0.5 \% \mathrm{HCl}, \mathrm{v} / \mathrm{v})$. The solvent to press cake ratio was $10: 1(\mathrm{v} / \mathrm{w})$. The extraction was carried out for 24 hours at ambient temperature with constant shaking.

Total anthocyanins content was measured by the $\mathrm{pH}$ differential method previously described by Lee et al. (2005). Juice and press cake extracts were added to $\mathrm{pH} 1.0$ and $\mathrm{pH} 4.5$ buffers and after an equilibration period $(20 \mathrm{~min})$, the absorbance was measured at 520 and $700 \mathrm{~nm}$ using a V-650 UV-vis spectrophotometer (Jasco Inc., Easton, USA). The corrected absorbance values were calculated as follows:

$$
A=\left(A_{520 \mathrm{~nm}}-A_{700 \mathrm{~nm}}\right) p H 1.0-\left(A_{520 \mathrm{~nm}}-A_{700 \mathrm{~nm}}\right) p H 4.5
$$

The total anthocyanin content was calculated using the molar absorptivity $(\epsilon=26,900)$ and molecular weight (MW=449.2) of cyanidin 3-glucoside. Results were expressed in $\mathrm{mg}$ of cyanidin 3-glucoside equivalents per $100 \mathrm{~mL}$ of juice or $100 \mathrm{~g}$ of press cake.

Total phenolics content was determined with the FolinCiocalteau reagent, following the procedure previously described by Bobinaite et al. (2012). After $1 \mathrm{~h}$ incubation of the reaction mixture, the absorbance of the samples was measured at $765 \mathrm{~nm}$ using a spectrophotometer. Gallic acid was used as a standard for the calibration curve and results were expressed in $\mathrm{mg}$ of gallic acid equivalents per $100 \mathrm{~mL}$ of juice or $100 \mathrm{~g}$ of press cake.

Ferric reducing absorbance power (FRAP) was determined following a slightly modified method of Benzie and Strain (1996). To conduct the assay, $2 \mathrm{~mL}$ of freshly prepared FRAP working solution was combined with $20 \mu \mathrm{L}$ of diluted juice or extract sample. After incubation for $30 \mathrm{~min}$ at ambient temperature, the absorbance of the samples was determined at $593 \mathrm{~nm}$ using a spectrophotometer. Trolox was used as a standard for the calibration curve and results were expressed as $\mu \mathrm{mol}$ of Trolox equivalents (TE) per $\mathrm{mL}$ of juice or $g$ of press cake.

Each experiment and analyses was repeated, at least, three times. Mean values and standard deviations of data were calculated. Significant differences between the results were calculated by analyses of variance (ANOVA). Mean values were further compared, using Turkey's test, and differences were considered to be statistically significant when $p \leq 0.05$. SPSS software, version 20 was used for statistical analysis (SPSS Inc., Chicago, USA).

\section{Results and Discussion}

The juice yield obtained from untreated and PEF treated sour cherries is shown in Figure 1. The juice yield was defined as the amount of juice $(\mathrm{g})$ obtained from $100 \mathrm{~g}$ of cherries. PEF assisted pressing led to significant increase in juice yield from $26.0 \mathrm{~g} 100 \mathrm{~g}^{-1}$

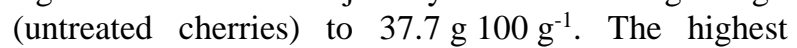
increase in juice yield (by $45 \%$ ) was achieved at the electric field strength of $3 \mathrm{kV} \mathrm{cm}^{-1}$, while higher values (up to $5 \mathrm{kV} \mathrm{cm}^{-1}$ ) did not lead to a further increase in juice yield. The results obtained were compared with other cell disintegration method, based on the freezethawing process. The formation of ice crystals during freezing cause damage (increase permeabilization) of plant cells thus can enhance the yield of fruit juice. In the present work, sour cherries were frozen to $-20{ }^{\circ} \mathrm{C}$ for $24 \mathrm{~h}$ and prior to juice pressing, they were thawed in the refrigerator. The juice yield obtained from

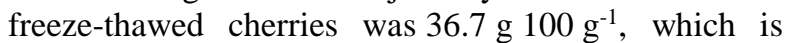
comparable to that of PEF-assisted pressing (when E was 1 and $3 \mathrm{kV} \mathrm{cm}^{-1}$ ) (Fig. 1).

Efficacy of the PEF treatment was also previously demonstrated for expression of juices from grapes, apples, carrots, and blueberries (MahnicKalamiza et al., 2014; Bobinaite et al., 2015). Moreover, it has been previously stated that the application of PEF can possibly replace or allow the reduction of the amount of pectolytic enzymes that are traditionally used in fruit juice production (Korma et al., 2016).

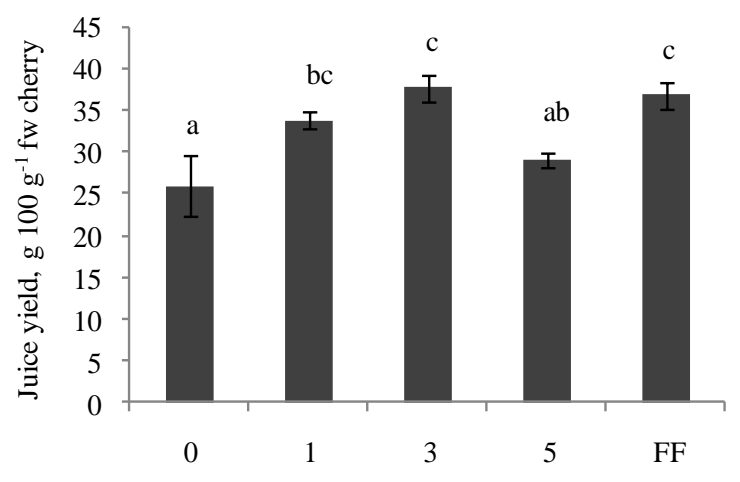

Figure 1. Juice yield obtained after pressing untreated, PEF-treated and frozen-thawed sour cherries

0 - untreated sample $\left(0 \mathrm{kV} \mathrm{cm}^{-1}\right), 1$ - PEF treated sample $\left(1 \mathrm{kV} \mathrm{cm}^{-1}\right), 3$ - PEF treated sample $\left(3 \mathrm{kV} \mathrm{cm}^{-1}\right), 5$ - PEF treated sample $\left(5 \mathrm{kV} \mathrm{cm}^{-1}\right), \mathrm{FF}$ - frozen and thawed sample. *different letters above bars indicate significant differences between the samples $(\mathrm{p} \leq 0.05)$.

Phenolic compounds, and in particular anthocyanins, are among the main components that determine berry juice quality and the efficiency of the pressing process. The total phenolics and anthocyanins content of PEF treated cherry juice and control juice is shown in Table 1. The total phenolics content of sour cherry juice after PEF application ranged between 126.6 and $133.9 \mathrm{mg} 100 \mathrm{~mL}^{-1}$, corresponding to $12-19 \%$ increment, compared to the untreated sample. Mechanical pressing of frozen and thawed sour cherries led to the highest release of phenolic compounds into juice, which corresponds to a $46 \%$ increase compared to the untreated sample.

The total monomeric anthocyanin content of sour cherry juices after PEF application was by 43 to $58 \%$ higher, compared to control sample. Interestingly, PEF assisted pressing of sour cherries led to the similar extraction yield of monomeric anthocyanins compared with that obtained from freeze thawed sample (Table 1). The lower content of monomeric 
anthocyanins in polyphenolic fraction of frozen-thawed cherry juice was most probably due to the enzymatic reactions that could take place in damaged sour cherry tissues during the thawing process.

Anthocyanins, in fact, are degraded by oxidative mechanisms involving the enzyme polyphenol oxidase (PPO). PPO is found in cherries and plays an important role in the browning of their fruit juices (Welch et al., 2008). Degraded anthocyanins are resistant to color changes regardless the $\mathrm{pH}$ of the media, therefore they are not included in the calculation applying $\mathrm{pH}$ differential method (Lee et al., 2005).

The increase in PEF treatment intensity to 3 and $5 \mathrm{kV} \mathrm{cm}^{-1}$ did not contribute to a more significant increase in the content of total phenolics and total anthocyanins in the juice (Table 1). These results are similar to those previously observed for blueberries, where it was noted that electric field strength higher than $1 \mathrm{kV} \mathrm{cm}^{-1}$ might not be necessary to facilitate the release of phenolic compounds into the juice (Bobinaite et al., 2015). A positive impact of PEF on extraction of polyphenols was also observed in juices obtained after PEF treatment of grapes (Grimi et al., 2009), blueberries (Bobinaite et al., 2015), and apples (Korma et al., 2016).

The juices obtained from PEF-treated cherries showed $25-36 \%$ higher FRAP values, while the control (untreated) sample displayed the minimum one (Table 1). The antioxidant activity of the juice from frozen and thawed cherries was by $51 \%$ higher compared to control sample. The increased ferric reducing absorbance power of the juices may be ascribed to an enhanced release of matrix-bound phenolic antioxidants.

PEF pre-treatment of plant tissues has also been reported to facilitate the diffusion of intracellular compounds during the subsequent extraction with solvent process (Mahnic-Kalamiza et al., 2014). Interestingly, in a previous work (Bobinaite et al., 2015), it has been shown that press cake extracts obtained after PEF-assisted pressing of blueberry fruits contained a higher amount of antioxidant compounds as compared with those of the extracts obtained without the application of PEF.

A similar approach was used in the present work. The results in terms of total phenolics and total anthocyanins content detected in the extracts obtained from the by-products (press cakes) of untreated, PEF treated and frozen-thawed cherries are shown in Table 2. The extraction yield of total phenolics and total anthocyanins obtained from the press cake of frozen-thawed cherries was comparable to that obtained from the control press cake sample, whereas the amount of total phenolics extracted from the press cake of PEF treated sour cherries was by 22-33\% higher and the amount of total anthocyanins by $44-54 \%$ higher compared to control extraction. A possible explanation is that pores formed during PEF treatment of sour cherries were still open after the juice pressing, thus leading to higher recovery yield of phenolic compounds.

Total phenolics, total anthocyanins and FRAP of sour cherry juice

\begin{tabular}{|c|c|c|c|}
\hline \multirow{2}{*}{ Samples } & Phenolics & Anthocyanins & \multirow{2}{*}{$\begin{array}{c}\text { FRAP } \\
\mu \mathrm{mol} \text { TE } \mathrm{mL}^{-1}\end{array}$} \\
\hline & \multicolumn{2}{|c|}{ mg $100 \mathrm{~mL}^{-1}$ juice } & \\
\hline $0 \mathrm{kV} \mathrm{cm}^{-1}$ & $112.90 \pm 4.22^{\mathrm{a}}$ & $33.80 \pm 6.83^{\mathrm{a}}$ & $4.90 \pm 0.22^{\mathrm{a}}$ \\
\hline $1 \mathrm{kVcm}^{-1}$ & $126.60 \pm 2.87^{\mathrm{b}}$ & $48.30 \pm 3.87^{b}$ & $6.10 \pm 0.66^{\mathrm{ab}}$ \\
\hline $3 \mathrm{kVcm}^{-1}$ & $132.80 \pm 6.48^{\mathrm{b}}$ & $49.90 \pm 3.85^{b}$ & $6.40 \pm 1.07^{\mathrm{b}}$ \\
\hline $5 \mathrm{kVcm}^{-1}$ & $133.90 \pm 2.67^{\mathrm{b}}$ & $53.30 \pm 0.97^{b}$ & $6.60 \pm 0.13^{\mathrm{b}}$ \\
\hline FF & $164.40 \pm 8.12^{\mathrm{c}}$ & $56.60 \pm 2.00^{\mathrm{b}}$ & $7.40 \pm 0.42^{\mathrm{b}}$ \\
\hline
\end{tabular}

$0 \mathrm{kV} \mathrm{cm}^{-1}$ - untreated (control) sample, FF - frozen and thawed sample.

*Different letters in the same column indicate significant differences between the samples $(\mathrm{p} \leq 0.05)$.

Table 2

Total phenolics, total anthocyanins and FRAP of extracts obtained from sour cherry press cake

\begin{tabular}{|c|c|c|c|}
\hline \multirow{2}{*}{ Samples } & Phenolics & Anthocyanins & \multirow{2}{*}{$\begin{array}{c}\text { FRAP } \\
\mu \mathrm{mol} \mathrm{TE}^{-1}\end{array}$} \\
\hline & \multicolumn{2}{|c|}{ mg $100 \mathrm{~g}^{-1}$ press cake } & \\
\hline $0 \mathrm{kV} \mathrm{cm}^{-1}$ & $304.90 \pm 13.18^{\mathrm{a}}$ & $109.40 \pm 6.66^{\mathrm{a}}$ & $45.30 \pm 3.76^{\mathrm{b}}$ \\
\hline $1 \mathrm{kVcm}^{-1}$ & $388.50 \pm 16.83^{\mathrm{b}}$ & $164.10 \pm 12.33^{\mathrm{b}}$ & $52.70 \pm 1.33^{\mathrm{bc}}$ \\
\hline $3 \mathrm{kVcm}^{-1}$ & $372.80 \pm 13.92^{\mathrm{b}}$ & $158.00 \pm 4.18^{\mathrm{b}}$ & $55.70 \pm 0.66^{\mathrm{c}}$ \\
\hline $5 \mathrm{kVcm}^{-1}$ & $407.90 \pm 18.54^{\mathrm{b}}$ & $168.50 \pm 3.99^{b}$ & $56.10 \pm 1.25 \mathrm{c}$ \\
\hline FF & $307.20 \pm 15.38^{\mathrm{a}}$ & $123.20 \pm 7.92^{\mathrm{a}}$ & $36.00 \pm 3.08^{\mathrm{a}}$ \\
\hline
\end{tabular}

$0 \mathrm{kV} \mathrm{cm}^{-1}$ - untreated (control) sample, $\mathrm{FF}$ - frozen and thawed sample.

*Different letters in the same column indicate significant differences between the samples $(p \leq 0.05)$. 
When PEF are applied in such way that irreversible permeabilization is achieved, some pores would never reseal, thus cell membrane is permanently damaged and therefore, the extraction process is facilitated.

Similarly to the results observed for sour cherry juice, electric field strength did not have significant $(\mathrm{p} \leq 0.05)$ influence on the extraction yield of total phenolics and total anthocyanins, i.e. higher electric field strength applied did not further enhance the extraction of phenolic compounds from sour cherry by-products (Table 2). Interestingly, in our previous work, the extractability of phenolic compounds from blueberry by-products was shown to be dependent on the applied electric field strength (Bobinaite et al., 2015). As it was previously documented, the influence of PEF treatment on extractability of phenolic compounds depends on the location of these compounds in the plant cell and also on the cell size distribution between berry skin and flesh (Corrales et al., 2008; Barba et al., 2015). In addition, it has been demonstrated previously that the effect of PEF might be very distinct even when applied to different fruit varieties of the same plant species (Donsi et al., 2010). PEF treatment of Aglianico grapes prior to the fermentation/maceration step induced a significantly higher release of polyphenols $(+20 \%)$ and anthocyanins $(+75 \%)$, whereas the same PEF treatment had only minor impact on the polyphenolic release from Piedirosso grapes (Donsi et al., 2010).

The extracts obtained from the by-products of PEF treated cherries possessed 16-24\% higher FRAP values with respect to control extract (obtained from untreated cherry press cake), while the extract obtained from freeze-thawed cherry by-products showed the lowest FRAP value. Moreover, FRAP of the extract obtained from press cake of frozen-thawed cherries was by $21 \%$ lower compared with the control.

It has been shown previously that PEF-assisted extraction of grape (Corrales et al., 2008), blueberry (Bobinaite et al., 2015), and raspberry (Lamanauskas et al., 2016) by-products increased the antioxidant activity of the extracts.

\section{Conclusions}

This study suggests that application of PEF in sour cherry juice production can enhance the juice yield and quality, as well as improve extraction efficiency of press cake residues.

The electric field strength of $1 \mathrm{kV} \mathrm{cm}^{-1}$ at the total specific energy input of $10 \mathrm{~kJ} \mathrm{~kg}^{-1}$ were shown to be sufficient for optimum PEF-assisted pre-treatment for sour cherry juice production and for further enhancement of extractability of anthocyanins and other phenolic compounds from the by-products (press cake).

\section{References}

1. Barba F. J., Galanakis C.M., Esteve M. J., Frigola A., Vorobiev E. (2015) Potential use of pulsed electric technologies and ultrasounds to improve the recovery of high-added value compounds from blackberries. Journal of Food Engineering, Vol. 167A, p. 38-44.

2. Benzie I. F., Strain J. J. (1996) The ferric reducing ability of plasma (FRAP) as a measure of "antioxidant power": The FRAP assay. Analytical Biochemistry,Vol. 1239, p. 70-76.

3. Blando F., Gerardi C., Nicoletti I. (2004) Sour cherry (PrunuscerasusL) anthocyanins as ingredients for functional foods. Journal of Biomedicine and Biotechnology, Vol. 5, p. 253-258.

4. Bobinaitè R., Viškelis P., Venskutonis P.R. (2012) Variation of total phenolics, anthocyanins, ellagic acid and radical scavenging capacity in various raspberry (Rubus spp.) cultivars. Food Chemistry, Vol. 132, p. 1495-1501.

5. Bobinaite R., Pataro G., Lamanauskas N., Šatkauskas S., Viškelis P., Ferrari G. (2015) Application of pulsed electric field in the production of juice and extraction of bioactive compounds from blueberry fruits and their by-products. Journal of Food Science and Technology, Vol. 52, p. 5898-5905.

6. Corrales M., Toepfl S., Butz P., Knorr D., Tauscher B. (2008) Extraction of anthocyanins from grape byproducts assisted by ultrasonics, high hydrostatic pressure or pulsed electric fields: A comparison. Innovative Food Science and Emerging Technologies, Vol. 9, p. 85-91.

7. Damar I., Eksi A. (2012) Antioxidant capacity and anthocyanin profile of sour cherry (Prunus cerasus L.) juice. Food Chemistry, Vol. 135, p. 2910-2914.

8. Donsi F., Ferrari G., Fruilo M., Pataro G. (2010) Pulsed electric field-assisted vinification of Aglianico and Piedirosso grapes. Journal of Agricultural and Food Chemistry, Vol. 58, p. 11606-11615.

9. Ferretti G., Bacchetti T., Belleggia A., Neri D. (2010) Cherry antioxidants: from farm to table. Molecules, Vol. 15, p. 6993-7005.

10. Grimi N., Lebovka N. I., Vorobiev E., Vaxelaire J. (2009) Effect of a pulsed electric field treatment on expression behavior and juice quality of Chardonnay grape. Food Biophysics, Vol. 4, p. 191-198.

11. Korma S. A., Kamal-Alahmad, Ali A. H, Shoaib M., Abed S. M., Yves H., Nsor-Atindana J., Qin J. (2016) Application of pulsed electric field technology in apple juice processing. Austin Journal of Nutrition and Food Science, Vol. 4, p. 1080.

12. Lamanauskas N., Pataro G., Bobinas Č., Šatkauskas S., Viškelis P., Bobinaite R., Ferrari G. (2016) Impact of pulsed electric field treatment on juice yield and recovery of bioactive compounds from raspberries and their byproducts. Zemdirbyste-Agriculture, Vol.103, p. 83-90.

13. Lee J., Durst R. W., Wrolstad R. E. (2005) Determination of total monomeric anthocyanin pigment content of fruit juices, beverages, natural colorants, and wines by the $\mathrm{pH}$ differential method: collaborative study. Journal of AOAC International, Vol. 88, p. 1269-1278.

14. Mahnic-Kalamiza S., Vorobiev E., Miklavčič D. (2014) Electroporation in food processing and biorefinery. Journal of Membrane Biology, 247, p. 1279-1304.

15. Ou B., Bosak K. N., Brickner P. R., Iezzoni D. G., Seymour E. M. (2012) Processed tart cherry productscomparative phytochemical content, in vitro antioxidant capacity and in vitro anti-inflammatory activity. Journal of Food Science, Vol. 77, p. 105-112. 
16. Repajić M., Kovačević D. B., Putnik P., Dragović-Uzelac V., Kušt J., Čošić Z., Levaj B. (2015) Influence of cultivar and industrial processing on polyphenols in concentrated sour cherry (Prunus cerasus L.) juice. Food Technology and Biotechnology, Vol. 53, p. 215-222.

17. Šarić A., Sobočanec S., Balog T., Kušić B., Šverko V., Dragović-Uzelac V., Levaj B., Čosić Z., Šafranko Ž. M.,
Marotti, T. (2009) Improved antioxidant and antiinflammatory potential in mice consuming sour cherry juice (Prunus cerasus cv. Maraska). Plant Foods for Human Nutrition, Vol. 64, p. 231-237.

18. Welch C. R., Wu Q., Simon J. E. (2008) Recent Advances in Anthocyanin Analysis and Characterization. Current Analytical Chemistry, Vol.4, p. 75-101. 